\title{
Estrategias y prácticas de inclusión de estudiantes migrantes en las escuelas de Arica y Parinacota, frontera norte de Chile ${ }^{1}$
}

\section{Strategies and inclusion practices of migrant students in Arica and Parinacota schools, northern border of Chile}

\author{
Carlos Mondaca ${ }^{2}$, Wilson Muñoz ${ }^{3}$, Yeliza Gajardo y Joaquín Gairín $^{5}$
}

\begin{abstract}
Resumen
El objetivo de este artículo es describir y caracterizar las estrategias y prácticas de inserción sociocultural de estudiantes migrantes (peruanos y bolivianos) en las escuelas de la región de Arica y Parinacota, Norte de Chile. Se analiza cómo el sistema educacional formal no ha desarrollado mecanismos institucionales de integración sociocultural que permitan una adecuada inserción de los estudiantes de origen extranjero en las escuelas chilenas; por lo cual, diversos agentes sociales (estudiantes, padres y apoderados) han debido desplegar estrategias y prácticas específicas de inserción adaptadas al contexto local, generando mecanismos emergentes de integración sociocultural.
\end{abstract}

Palabras claves: integración sociocultural, migración, educación, norte de Chile.

\begin{abstract}
The aim of this article is to describe and characterize the strategies and sociocultural insertion practices in migrant students (Peruvians and Bolivians) in schools located in the Arica and Parinacota region, Northern Chile. It is analyzed how the formal educational system has not developed institutional mechanisms of sociocultural integration that allow an appropiate insertion to foreign students in chilean schools, whereby, different social agents (students, parents and representatives) have had to display strategies and specific insertion practices adapted to the local context, generating emerging mechanisms of sociocultural integration.
\end{abstract}

Keywords: sociocultural insertion, migration, education, north of Chile.

Recibido: 15 marzo 2016. Aceptado: 6 noviembre 2016.

1 El presente artículo es resultado de los proyectos FONDECYT 1160976 y UTA 5711-15. Se agradece el apoyo del Convenio Marco Formación Inicial Docente, UTA1756.

2 Académico del Departamento de Educación de la Universidad de Tarapacá-Chile. Doctorando en Educación, Universitat Autònoma de Barcelona. CHILE. Email: cemondacar@uta.cl

3 Investigador doctoral del Laboratoire d'Anthropologie Sociale (LAS), Collège de France/ EHESS/ CNRS/PSL Research University, Francia.Investigador asociado de la Universidad de Tarapacá-Chile. Investigador asociado del Grup de Investigacions en Sociologia de la Religió (ISOR), Universidad Autónoma de Barcelona. Becario Conicyt (Becas Chile). CHILE. Email: wilsonsocio@gmail.com

4 Departamento de Educación de la Universidad de Tarapacá-Chile. Estudiante Magíster en Didáctica del Lenguaje, Universidad Alberto Hurtado-Chile. Co-investigadora Proyecto Fondecyt 1130859. CHILE. Email: Correo electrónico: ygajardo@uta.cl

5 Profesor Catedrático de la Universitat Autònoma de Barcelona. Doctor en Educación, director del Grupo internacional EDO y de la Red de Apoyo a la Gestión Educativa (RedAGE). ESPAÑA. Email: joaquin.gairin@uab.es 


\section{Introducción}

En las últimas décadas la migración desarrollada en un contexto globalizado ha impulsado importantes transformaciones económicas, políticas, sociales y culturales (Appadurai, 2000). Pero si bien la globalización ha permitido que las barreras comerciales se hayan flexibilizado, las fronteras sociales y humanas no han tenido la misma suerte (Nubia, 2005, en Riquelme y Alarcón, 2008), especialmente en contextos caracterizados por un bajo crecimiento económico. En muchas regiones de América Latina (Colombia, Ecuador, Perú, Bolivia, México y Argentina), coexisten múltiples flujos migratorios entre diferentes naciones (Castles y Miller, 2004), manifestándose una estructura bipolar del fenómeno: por un lado existen grandes países emisores de emigrantes, y por otro lado tenemos un puñado de países receptores de estos inmigrantes (CEPAL, 2006; Sorensen y Gammeltoft-Hansen, 2013).

Este fenómeno se evidencia claramente en la región fronteriza de Arica y Parinacota, que colinda con Perú y Bolivia y es la puerta de entrada norte a Chile (Tapia, 2014). Esta zona posee una diversidad sociocultural distintiva y de profundas raíces históricas, como mostraremos brevemente a continuación con el fin de contextualizar este fenómeno en la región. La arqueología regional ha utilizado el concepto de multietnicidad para definir la red de relaciones establecidas entre los primeros pueblos que ocuparon los distintos pisos ecológicos de esta zona. Estas relaciones de interacción social originarias se complejizaron con la llegada de los hispanos y la población afrodescendiente de fines del siglo XVI en adelante, lo que fue generando un escenario colonial transcultural. ${ }^{6}$ La configuración del mundo colonial también fue afectada por los movimientos emancipatorios de América Latina, los que trajeron consigo la conformación de las Estados nacionales y el nacimiento de nuevos países, reestructurando nuevamente el escenario cultural regional.

Posteriormente, tanto los movimientos migratorios internos gatillados por los cambios políticos y eco-

6 Esto es visible hasta el día de hoy en diversas manifestaciones culturales de la población regional, donde lo indígena, lo afro y lo español están potentemente imbricados. nómicos del siglo XIX como también la inmigración extranjera marcaron el tenor de un nuevo contexto sociocultural. A comienzos del siglo XIX la zona recibió una oleada de inmigrantes europeos (croatas, italianos, franceses, españoles, griegos, ingleses, alemanes) y orientales (chinos y japoneses), los que fueron estableciendo relaciones parentales con los locales y se asentaron definitivamente en Arica y Parinacota. Debido a las diversas actividades económicas que desempeñaban, fueron un aporte clave para el desarrollo de la región. Posteriormente, durante la segunda mitad del siglo XIX el escenario se tornó mucho más complejo, debido al conflicto de la Guerra del Pacífico. La disputa por el territorio se manifestó en un proceso político único, donde la zona quedó en una negociación de statu quo que se definió entre las repúblicas de Chile y Perú recién en 1929. Para el caso peruano, esto implicó la salida de muchos de sus coterráneos de la zona, producto del proceso de chilenización; mientras que para el caso chileno implicó el traslado de mucha población desde el sur del país y su posterior concentración en Arica, actividad que fue fomentada por el Estado en diversas ocasiones.

A inicios del siglo XX la región poseía variadas poblaciones asentadas y un importante crisol de nacionalidades. Un punto de inflexión en materia de diversidad se configuró a partir de la creación del Puerto Libre y de la Junta de Adelanto de Arica. Estas iniciativas políticas no solo generaron un polo de desarrollo económico, sino que también provocaron una atracción de población local y nacional, destacándose la migración translocal de la población originaria del interior de Arica. El crecimiento demográfico y la diversificación cultural de la zona se han incrementado aún más en los últimos 30 años, especialmente por la constante migración transfronteriza de grupos bolivianos y peruanos.

Si bien esta migración posee larga data en la región, el proceso de reconfiguración sociocultural de la zona se ha visto transformado por las nuevas dinámicas migratorias desarrolladas en el contexto de la globalización (Guizardi y Garcés, 2012; Garcés, 2015). Según los datos del Censo 2012 (que solo lo utilizamos como referencia en relación al de 2002), los extranjeros representarían el 5,8\% de la población total (12.299 personas), donde los bolivianos corresponderían al $48 \%$ de la población migrante 
regional (5.903 personas) y los peruanos al 39,6\%. Uno de los factores gravitantes de este fenómeno es el empuje del mercado laboral de la región, lo que le ha permitido constituirse en una alternativa económica viable para muchos inmigrantes de origen peruano y boliviano (Tapia y González, 2104; Rojas y Vicuña, 2014; Imilan et al., 2015; Vicuña y Rojas, 2015; Pavez, 2012). Finalmente este flujo migratorio ha permitido y catalizado importantes procesos de intercambio económico, político y sociocultural en la zona (Pulido, 2007).
Uno de los ámbitos más influenciados por esta pujante migración peruana y boliviana en la región es el educativo. Los hijos de los migrantes se han ido incorporando crecientemente a las aulas del sistema educativo, generando un escenario intercultural emergente que está planteando importantes desafíos al sistema educativo local y nacional. La presencia y distribución de estos alumnos extranjeros en los establecimientos educativos de Chile puede apreciarse en la siguiente tabla:

Tabla 1. Total de matrículas de alumnos extranjeros por procedencia y por tipo de dependencia de los establecimientos educacionales de la región de Arica y Parinacota.

\begin{tabular}{|c|c|c|c|c|c|c|c|c|c|c|c|}
\hline $\begin{array}{l}\text { Tipos de estable- } \\
\text { cimientos según } \\
\text { tipo educacional y } \\
\text { comuna }\end{array}$ & $\begin{array}{l}Z \\
0 \\
3 \\
\vdots \\
\vdots \\
\vdots \\
\vdots \\
2\end{array}$ & 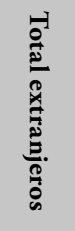 & 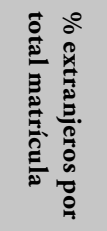 & 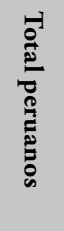 & 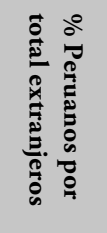 & 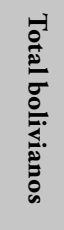 & 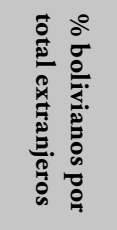 & 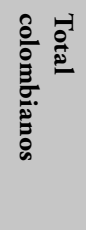 & 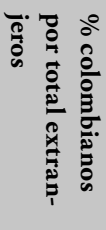 & 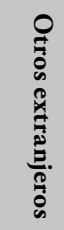 & $\begin{array}{cc}0 & 0 \\
0 & 0 \\
0 & 0 \\
0 & 0 \\
0 & 0 \\
0 & 0 \\
0 & 0 \\
0 & 0 \\
0 & 0 \\
0 & 0\end{array}$ \\
\hline $\begin{array}{l}\text { Comuna Arica } \\
\text { Municipales } \\
\text { urbanos }\end{array}$ & 15593 & 1042 & $6,68 \%$ & 432 & $41,45 \%$ & 471 & $45,20 \%$ & 72 & $6,90 \%$ & 67 & $6,42 \%$ \\
\hline $\begin{array}{l}\text { Comuna Arica } \\
\text { Municipales rurales }\end{array}$ & 2378 & 436 & $18,33 \%$ & 164 & $37,61 \%$ & 270 & $61,92 \%$ & 0 & $0,00 \%$ & 2 & $0,45 \%$ \\
\hline $\begin{array}{l}\text { Comuna Arica } \\
\text { Particulares } \\
\text { subvencionados } \\
\text { (básico, media y } \\
\text { adultos) }\end{array}$ & 28042 & 660 & $2,35 \%$ & 276 & $41,86 \%$ & 261 & $39,54 \%$ & 49 & $7,42 \%$ & 74 & $11,21 \%$ \\
\hline $\begin{array}{l}\text { Comuna Arica } \\
\text { Particulares } \\
\text { subvencionados } \\
\text { (especiales y } \\
\text { jardines infantiles) }\end{array}$ & 3072 & 39 & $1,26 \%$ & 20 & $51,28 \%$ & 8 & $20,51 \%$ & 5 & $12,82 \%$ & 6 & $15,38 \%$ \\
\hline $\begin{array}{l}\text { Comuna Arica } \\
\text { Particulares } \\
\text { Pagados }\end{array}$ & 1812 & 36 & $1,98 \%$ & 12 & $33,33 \%$ & 5 & $13,88 \%$ & 1 & $2,77 \%$ & 18 & $50,00 \%$ \\
\hline $\begin{array}{l}\text { Comuna de } \\
\text { Camarones } \\
\text { Municipales rurales }\end{array}$ & 84 & 9 & $10,71 \%$ & 2 & $22,22 \%$ & 7 & $77,77 \%$ & 0 & $0,00 \%$ & 0 & $0,00 \%$ \\
\hline $\begin{array}{l}\text { Comuna de } \\
\text { General Lagos } \\
\text { Municipales rurales }\end{array}$ & 51 & 15 & $29,41 \%$ & 0 & $0,00 \%$ & 15 & $100,00 \%$ & 0 & $0,00 \%$ & 0 & $0,00 \%$ \\
\hline $\begin{array}{l}\text { Comuna de Putre } \\
\text { Municipales rurales }\end{array}$ & 229 & 71 & $31,00 \%$ & 8 & $11,26 \%$ & 63 & $88,73 \%$ & 0 & $0,00 \%$ & 0 & $0,00 \%$ \\
\hline $\begin{array}{l}\text { TOTAL } \\
\text { MATRÍCULA }\end{array}$ & 50897 & 2213 & $4,34 \%$ & 904 & $40,84 \%$ & 1015 & $45,86 \%$ & 127 & $5,73 \%$ & 167 & $7,54 \%$ \\
\hline
\end{tabular}

Fuente: Elaboración propia a partir de datos recolectados en el Proyecto Fondecyt 1160976. 
Consideramos que en un contexto transfronterizo y marcado históricamente por la diversidad sociocultural como es la región de Arica y Parinacota, donde existe una creciente presencia de población de inmigrantes (como muestra la tabla anterior); el sistema educativo debe poseer herramientas que contribuyan a la integración de estudiantes de orígenes y características diversos, propiciando así la generación de ciudadanos interculturales acordes a esta realidad (Poblete, 2009; Gairín y Castro, 2010). Para ello, primero es necesario conocer cómo este sistema educativo está reaccionando ante la creciente presencia de estudiantes de origen extranjero. Si bien esta descripción es clave para generar cualquier tipo de diagnóstico o evaluación de cara a generar iniciativas políticas que permitan mejorar la integración en el sistema educativo, actualmente no existen estudios que nos entreguen información detallada sobre este fenómeno.

A partir del análisis de datos empíricos realizado en el proyecto Fondecyt 1160976, este artículo busca realizar una contribución al respecto. Su objetivo es describir y caracterizar las estrategias y prácticas de inserción sociocultural de estudiantes migrantes (peruanos y bolivianos) en las escuelas de la región de Arica y Parinacota. Nuestra hipótesis de trabajo es que, dado que el sistema educacional formal no ha desarrollado mecanismos institucionales de integración sociocultural que permitan una adecuada inserción de los estudiantes de origen extranjero en las escuelas, diversos actores sociales (estudiantes, padres y apoderados) han debido desplegar estrategias y prácticas específicas de inserción adaptadas al contexto local, generando mecanismos emergentes de integración sociocultural. Consideramos que estos hallazgos permitirán dar a conocer y analizar un fenómeno en expansión que caracteriza a esta región limítrofe. Además, esperamos que la descripción y caracterización de estos mecanismos de inserción emergentes presentes en el sistema educativo local sean considerados a la hora de planificar y desarrollar proyectos y políticas públicas orientados a la integración creciente de esta población en la región, desde la lógica de una educación para la ciudadanía intercultural.

\section{Metodología de trabajo}

Para alcanzar nuestro objetivo y testear nuestra hipótesis de trabajo, hemos utilizado un acercamiento cualitativo, pues esta metodología es especialmente sensible para relevar información sobre el sentido atribuido a las prácticas socioculturales en contextos de diversidad cultural (Flick, 2002; Willis y Trondman, 2002). Con el fin de asegurar una mayor variabilidad en la obtención de información, seleccionamos cuatro casos de estudio diferentes. Los casos específicos y los criterios de selección utilizados fueron los siguientes: Caso 1: Institución de enseñanza media técnico-profesional, municipal, con alta presencia de estudiantes inmigrantes y ubicada en el valle de Azapa (rural). Caso 2: Institución de enseńanza media técnico-profesional, municipal, con presencia de estudiantes inmigrantes y ubicada en la ciudad de Arica (urbano). Caso 3: Institución de enseñanza básica, municipal, con alta presencia de estudiantes inmigrantes y ubicada en el valle de Lluta (rural). Caso 4: Institución de enseñanza básica, municipal, con presencia de estudiantes inmigrantes y ubicada en la ciudad de Arica (urbano).

Dentro de cada caso de estudio seleccionamos a los siguientes informantes: cuatro profesores que tuvieran a su cargo alguno de los cursos con la mayor cantidad de estudiantes inmigrantes, tres apoderados inmigrantes, un apoderado chileno que tuviera contacto con cada uno de los profesores seleccionados, tres alumnos/hijos de cada uno de los apoderados inmigrantes seleccionados y un alumno hijo del apoderado chileno. Como técnica de recolección de información utilizamos la entrevista semiestructurada en profundidad, que fue aplicada de manera diferenciada a cada uno de los informantes seleccionados. Finalmente, los datos recolectados fueron analizados utilizando la técnica de análisis de contenido (Pińuela, 2002).

\section{Chilenización, diversidad cultural y el rol de la escuela}

Desde la ocupación que las tropas chilenas realizaron de la zona de estudio durante la Guerra del Pacífico, la población otrora peruana, boliviana, andina $y$ afrodescendiente, se vio enfrentada a un proceso 
de asimilación nacionalista conocido como chilenización. Por medio de la administración política, económica, social y cultural de estos territorios, este proceso disciplinó a esta población con el fin de convertir su antigua adscripción ciudadana en chilena (Aguirre y Mondaca, 2011; Mondaca et al., 2013).

Existió una importante articulación sociopolítica y sociocultural en el contexto de la chilenización, donde uno de los mecanismos claves de la asimilación y el disciplinamiento por parte del Estado fue la escuela. Ésta tendrá una fuerte tendencia a la homogenización del acervo cultural de la población que vivía en esta área de frontera, imponiendo los valores patrios que imperaban a fines del siglo XIX y gran parte del siglo XX en el país (Mondaca, 2008). ${ }^{7}$

Partiendo de la lectura de los trabajos de González (2002) y de Castro (2004), es posible sostener la idea de que no fue el Estado el que implementó la escuela en Tarapacá, por lo menos hasta 1930. Se habría tratado más bien de una iniciativa de los propios comuneros y habitantes del norte de Chile. La evidencia empírica para el caso de Arica lo confirma, pues su población ayudó decididamente a llevar la escuela pública a sus diversas localidades, e incluso pagó a preceptores para la instalación de escuelas privadas en el área urbana (Mondaca, 2008). De ahí en adelante, tanto la escuela fiscal como los profesores normalistas tendrán un rol preponderante en la educación e impondrán las ideas nacionalistas en la zona y el país entero. No será hasta la década de los noventa que el Estado comenzará a impulsar políticas que consideren la diversidad étnica de sus estudiantes, lo que se evidencia en el Programa de educación intercultural bilingüe (en adelante EIB).

\section{De la EIB a la inclusión educativa e intercultural de inmigrantes}

A fines de la década del noventa se comenzaron a estudiar los procesos de implementación de la política

7 La red de escuelas estuvo orientada hacia propósitos nacionalistas desde fines del siglo XIX hasta fines del siglo XX. Solo a partir de los años noventa comenzaron a considerarse las particularidades rurales y luego indígenas de la zona (Mondaca, 2003; Mondaca y Gajardo, 2013). pública en materia de EIB en la región ${ }^{8}$ (Mondaca, 2003). En los últimos años, tanto el diagnóstico como el análisis generado al respecto se ha ido complejizando. Se cuestionaron los mecanismos de inclusión de la diversidad que operan en las escuelas, abriendo un abanico de posibilidades de investigación sobre los diversos ambientes socioeducativos que caracterizaban a las aulas de la región. Así, aspectos como las prácticas pedagógicas, el currículum, el clima educacional o el entorno social aparecen fuertemente atravesados por fenómenos como la interculturalidad y la inclusión/exclusión. Estos últimos se han convertido en temas especialmente problemáticos y relevantes para la política educativa y la investigación.

Los conceptos de interculturalidad e inclusión han sido parte de una confusión en la política pública educativa chilena. Durante los últimos 20 años, la mayoría de nuestros educadores han asociado la educación intercultural con lo indígena, y de manera casi exclusiva con la EIB (Mondaca, 2003; Mondaca y Gajardo, 2013). Consideramos que es necesario contribuir o edificar una conceptualización de interculturalidad a nivel de modelo o paradigma educativo, superando la mera asociación con la educación étnica (inmigrantes, grupos vulnerables, desigualdad social, diversidad cultural, etc.) (Mondaca, 2003; Mineduc, 2011). Una situación similar ocurre con el concepto de inclusión, pues los docentes suelen asociarlo únicamente a la satisfacción de necesidades educativas especiales o específicas, obviando el amplio espectro de ámbitos que involucra la inclusión (diversidad sexual, cultural, de creencias, etc.).

Consideramos que una educación inclusiva debe considerar el diálogo intercultural como un eje central de desarrollo, donde la formación educativa es una práctica pedagógica que tiene que basarse en el reconocimiento de la diversidad, la participación comunitaria y una eficiente gestión directiva y escolar en materia de currículum que articule contextos culturales diferentes. Así emerge una verdadera educación intercultural, cuyo objetivo es que los

8 El año 2006 esta región se dividió en dos nuevas regiones administrativas: la I región de Tarapacá y la XV de Arica y Parinacota. 
diversos estudiantes puedan desenvolverse en diferentes mundos culturales con eficiencia y eficacia escolares. Pero el principal problema ante este desafío es la institucionalidad y la gestión escolar, pues no manifiesta una apertura hacia la interculturalidad en la región. En este sentido, en la medida que la institucionalidad siga centrada en la transmisión de saberes hegemónicos emanados desde el Estado nacional y organizados en las disciplinas escolares, es difícil integrar la interculturalidad.

La incorporación de una ciudadanía intercultural es clave para sortear esta problemática. Seguimos a Marshall (1950) cuando señalaba que la pertenencia plena a una comunidad está dada por la obtención de derechos sociales emanados desde las comunidades locales y asociaciones funcionales. Esta ciudadanía se sostiene en un marco político, cívico y social que otorga una membresía única e indivisible. Esta membresía ha sido conquistada en el trayecto de las luchas políticas y sociales que interrelacionan a los ciudadanos con el Estado, en el marco de las instituciones y la sociedad. Sin embargo, esta ciudadanía intercultural no es meramente un estatus definido por la posesión de derechos y responsabilidades concebidos bajo el Estado-nación. Se trata también de una estructura de identidad política que denota la pertenencia a un grupo en particular. De manera que es perfectamente compatible la participación plena en el Estado-nación, con la coexistencia de diversidades culturales en su constitución. Así, esta identidad podría ser compartida tanto por los actores sociales como por el Estado. Ambos elementos convivirían en un mismo momento histórico en que la ciudadanía intercultural no se identifica con la homogeneidad nacional, sino que se abre a la diferencia en general. Sin embargo, su configuración específica dependerá de los contextos locales e históricos en los cuales los propios agentes articulen sus posiciones de participación en y con las instituciones del Estado.

La construcción de este proceso de participación ciudadana tendrá como soporte la identidad cultural y las etnicidades como referente ideológico sociopolítico. Cuando hablamos de diversidad cultural e identidades nos referimos a los esterotipos sociales que se manifiestan en miembros de un grupo, ya sea que ellos mismos se las adjudiquen, u otros, lo que supone el reconocimiento implícito de que toda persona vive con un sentido múltiple de sí misma y puede desarrollar posiciones de identidades dispares y contradictorias (AlSayyad y Castells, 2003) Considerando esto, se comprende por qué la identidad depende cada vez más de un conjunto de fuentes como la nacionalidad, la etnicidad, la clase social, la comunidad, la sexualidad y el género, las que pueden entrar en conflicto. De allí la necesidad de tratar de impulsar un acuerdo intercultural donde la identidad se halle siempre en formación y evolución, en una interacción de negociación cultural que tiene forma de diálogo cultural (Tibi, 2003, en AlSayyad y Castells, 2003).

Por ello, es necesario y factible asumir una postura que abogue por una ciudadanía intercultural compuesta por identidades múltiples en su relación cotidiana con el Estado (Kumar, 2002). Se trata de una ciudadanía entendida más como una membresía con una comunidad (Yuval-Davis, 1997) que con el Estado mismo, como suele hacerlo la concepción liberal. En este sentido, es la misma definición de Marshall (1950) la que nos permite discutir analíticamente la ciudadanía como un constructo elaborado a partir de múltiples niveles, aplicable a miembros de varias colectividades locales étnicas, nacionales y transnacionales.

Desde el ámbito pedagógico y educativo es posible realizar estrategias didácticas que consideren a los migrantes, pueblos originarios y chilenos como parte de una comunidad y de sus instituciones políticas, económicas, sociales y culturales. Todo en una relación de igualdad con sus pares y a través del ejercicio de sus derechos y deberes, donde el Estado-nación funcione como un ente político inclusivo y no un asimilador de diferencias culturales. En su seno educativo se deberían fomentar los cruces interculturales por razones económicas, comunicativas, cognoscitivas u otras; pero a la vez, acrecentar las posibilidades de diálogo en estos encuentros, reconociendo diferencias y derechos que potencialmente favorecerían el desarrollo de la comunicación intercultural e inclusiva en nuestras aulas (Winkler y Cueto, 2004). Esta propuesta debe incorporar el fenómeno de la inclusión de migran- 
tes, pueblos originarios y chilenos en las escuelas de la región, tomando en consideración la diversidad desde lineamientos que fomenten la formación de un ciudadano intercultural inclusivo desde las aulas (Gimeno, 2008; Martínez, 2008), basados en el conocimiento de su historia e identidad cultural a nivel local y global.

\section{Procesos de inclusión y exclusión en las escuelas de la frontera norte de Chile}

$\mathrm{Al}$ analizar la información empírica que hemos recolectado, observamos cómo diversos agentes de la comunidad escolar han desarrollado diversas estrategias y prácticas para alcanzar la integración sociocultural de los estudiantes de origen extranjero en el sistema educativo local. A continuación, mostramos cómo se manifiestan estos mecanismos en el ámbito de la integración, i) personal y familiar, ii) pares (compańeros) y docentes y, iii) a nivel institucional (políticas y establecimiento). Finalmente, establecemos algunas conclusiones generales sobre cada uno de estos ámbitos y proponemos una sugerencia para la política pública enfocada a mejorar la integración sociocultural de estudiantes de origen extranjero en el sistema educativo local y nacional.

\section{Integración personal y familiar}

Los hallazgos evidencian que los estudiantes de origen extranjero pertenecen a familias que han emigrado a Chile principalmente en busca de mejoras económico-laborales y, en menor medida, de un acceso a una mejor educación. Gran parte de las familias pertenecen a estratos socioeconómicos mediosbajos o bajos y laboralmente suelen desempeñarse en labores de poca calificación (agricultura, labores domésticas, manipuladores de alimentos, etc.), recibiendo remuneraciones relativamente bajas y realizando extensas jornadas laborales (especialmente en el caso rural).

La inserción en el ámbito local a nivel social y económico no resultó fácil en sus inicios para la mayoría de las familias extranjeras, pues debieron sortear una serie de dificultades de integración propias de la experiencia de migrar a otro país, tal y como nos in- dicó una apoderada de nacionalidad peruana: "Los primeros meses estaba un poco preocupada; las primeras semanas preocupada por el tema del trabajo, porque ése era uno de los objetivos para mantener a mis hijas. Eso era lo principal. En el ámbito social ha sido tranquilo, no en todos sí que lo fue, ya que empecé a trabajar haciendo limpieza en la casa y la señora como que no me trató bien y solo duré dos semanas. Tengo actualmente otro trabajo y está todo bien" (SS-AP).

Estas familias han dejado a gran parte de sus redes de familiares cercanos, extensos y amistades, que solían ser parte de su entorno familiar y social en el país de origen, y que funcionaban como un círculo de cooperación importante para sortear sus dificultades socioeconómicas. Esto está en concordancia con las evidencias de trabajos anteriores sobre inmigrantes peruanas y trabajo doméstico (Guizardi y Garcés, 2012, 2013), y sobre las redes de parentesco de los inmigrantes en la zona (Garcés, 2015). Lo interesante es que entre las personas que habitan en las ciudades de Tacna y Arica existen lazos de parentesco, además de una cercanía física y la posibilidad de realizar una permanencia semanal laboral en Arica. Ambos aspectos configuran un escenario bastante particular de cooperación y de mayor movilidad de inmigrantes hacia nuestra ciudad.

También estas familias han superado una serie de limitaciones legales y policiales existentes en Chile para obtener su residencia (ya sea laboral o definitiva), la cual les permite trabajar por períodos sostenidos en el tiempo y acceder a diversos beneficios socioeconómicos, tanto a nivel público (subsidios, ayudas estatales, etc.) como privado (créditos, etc.). Por ejemplo, una vez que un niño, niña o adolescente extranjero es recibido en un colegio como estudiante, debe comenzar el período de regularización antes de siete días (plazo máximo), aunque sus padres estén en situación de ilegales en el país.

Este último factor es clave pues, como se mencionaba anteriormente, la mayoría de las familias migrantes ingresa en el país en busca de mejoras sustanciales en el plano económico-laboral. Este es su principal objetivo (explícito) y de ahí la importancia que para ellos tiene obtener un trabajo, como señaló una docente: "Ellos priorizan mucho lo que es el 
trabajo, porque ellos trabajan de sol a sol. Entonces, priorizan mucho esa parte, sí, muchos de ellos, casi la totalidad de los padres extranjeros se tiene que ir a Chile, porque claro, la renta es mayor o mejor que en su país, entonces ellos dedican mucho tiempo a su trabajo, y hay veces en que trabaja papá y mamá” (DM-ER).

En este sentido, hemos podido advertir que uno de los ámbitos principales donde se busca y alcanza una integración en el país de destino es en el laboral-económico. De esta forma, las redes sociales suelen generarse y reproducirse a partir del ámbito laboral, sobre todo entre connacionales. Este fenómeno es relevante para comprender la relación que normalmente establecen las familias de origen extranjero con otros ámbitos como el educativo, pues los datos evidencian que este último suele resultar un espacio de integración menor y secundario respecto al laboral.

\section{La limitada participación de los apoderados}

Un grupo de docentes y apoderados destaca que la participación de los padres y apoderados, tanto en las actividades formales como informales desarrolladas en escuelas y liceos, es baja y muy limitada. La actividad principal y obligatoria es la reunión mensual, donde suelen asistir e interactuar con otros apoderados y el docente, en la medida que lo permite esta limitada instancia.

En las actividades que se desarrollan de manera libre muy pocos de los padres y apoderados (tanto de origen extranjero como chilenos) suelen participar. La inmensa mayoría de docentes señala que se trata de un problema presente en todo el establecimiento y en la educación en general: los padres y apoderados no suelen establecer vínculos de cooperación y participación estrecha con el resto de la comunidad escolar y sus relacionados.

Los apoderados sostienen que existen al menos tres limitaciones principales que afectan su participación en las actividades programáticas y extraprogramáticas que les ofrece el colegio. Por un lado, se señala que no existen instancias concretas para poder participar más allá de la reunión mensual de apoderados. Por otro lado, sostienen que las actividades que promueven los establecimientos suelen realizarse en horarios que están reñidos con sus extensas jornadas laborales. Y por último, arguyen que de las pocas actividades que se realizan, ninguna de ellas está realmente orientada a fomentar la integración social, cultural y educativa de los estudiantes de origen extranjero que asisten al establecimiento educativo, ni muchos menos a dar acogida a sus padres y apoderados en cuanto familias.

En este contexto, la consigna para lograr una adecuada integración dentro del ámbito educativo, tanto en el plano social como cultural, resulta clara y unívoca. Como bien señaló una de las apoderadas peruanas: "Uno se tiene que adaptar nomás" (AMLR-P). Entre otras cosas porque, en general, no existen políticas formales ni estrategias informales destinadas a generar una acogida de estas familias en los establecimientos educacionales, ni tampoco el fomento a la integración sociocultural de sus hijos en este ámbito.

Los docentes también subrayan que una de las principales limitantes que enfrentan los apoderados para participar en las actividades desarrolladas por los establecimientos son sus horarios laborales. Esto se aprecia de manera más clara en el caso rural, donde la mayoría de apoderados trabaja en el sector agrícola y debe cumplir extensas jornadas laborales, lo que termina mermando considerablemente su participación en las actividades de las escuelas y liceos de sus hijos. Una de las docentes, a la hora de ser consultada por el origen de esta baja participación de los apoderados, contestó lo siguiente: "Acá prima harto el trabajo. Acá ellos trabajan mucho lo que es la chacra, agricultores. Entonces ellos no tienen tiempo, porque ellos trabajan de sol a sol, entonces al estar así, son como muy independientes, y ellos tienen que ver su producción, entonces no les deja tiempo para venir. De hecho, por ejemplo a las reuniones de apoderados, uno los cita y [son] contados los que vienen. Yo tengo que estar llamando de mi teléfono, 'oiga, pero venga, pero venga', como cateteando para que vengan” (DM, ER).

Otro docente de un liceo rural confirma que "por lo general, los extranjeros bolivianos y peruanos que llegan a habitar al valle provienen de localidades rurales, por lo que siempre han estado relacionados 
con la actividad agrícola" (LB, EA); por lo tanto, sus trabajos se limitan a esta área laboral y su condición como apoderados se ve mucho más restringida a la hora de asistir a las actividades escolares, básicamente por falta de tiempo.

Algunos docentes señalaron que esta excesiva carga de trabajo de los apoderados no solo causaba su escasa presencia en las actividades en los colegios, sino también en sus mismos hogares. Según ellos, esto ha provocado importantes problemas familiares que han afectado directamente a sus hijos, especialmente en su desarrollo personal e integración educacional: "A veces se ven reflejados los problemas que tienen en la casa. Por ejemplo, la carencia de preocupación que a veces tienen los papás: se preocupan del trabajo y no se preocupan de los niños de cierta forma [...] que están súper faltos de cariño y muy solitos. Siempre buscan que uno los acoja, que los escuche; hay que escucharlos mucho, porque vienen con sus historias, con sus penas, lo que les ha pasado y eso es como un martirio para mí, además de buscar que uno los apoye en cuanto a lo académico" (DM-ER).

Este panorama es confirmado por otros docentes. Uno de ellos nos indica que "hay muchos niños que viven en unas parcelas, y en las parcelas que están, no trabajan en esa misma parcela, van a trabajar al kilómetro cinco, y los niños viven en el quince, supongamos. Y sus papás van a trabajar al kilómetro cinco o después se van al siete, o después se van al veinte, ¿me entiendes? Y trabajan todo el día ahí po, trabajando la tierra y todo ese tipo de cosas, que los contratan más personas, entonces, obviamente llegan tarde. $\mathrm{O}$ hay papás que trabajan en las parcelas donde ellos están, pero trabajan todo el día atendiendo a las personas, porque la gente que se dedica a la agricultura tiene que sembrar y abonar, y luego cuando se vienen las cosechas no pueden sacar las cosechas solos, tienen que contratar gente y tienen que atender a toda esa gente. Y los niños, muchos acá se preocupan de sus hermanos menores, muchos me dicen 'señorita, no lo pude hacer porque tuve que cuidar a mi hermana', y como sus papás se van a trabajar, ellos los dejan cuidando a los niños más pequeñitos" (D- PB-G8).

Un docente de un liceo rural nos entregó dos datos importantes al respecto. El primero de ellos es que se establece una diferencia en la participación y el compromiso de los apoderados según la edad y el nivel que cursan sus estudiantes, indicando que "existen apoderados extranjeros que se preocupan mucho sobre cómo sus pupilos están relacionándose en sus cursos, principalmente en los más pequeños (nivel prebásico hasta cuarto básico), ya en el segundo ciclo de la básica y la enseńanza media los padres extranjeros de cierta forma se despreocupan un poco más de sus hijos en cuanto a que sean integrados por sus compañeros" (D-LR). El segundo dato importante que señaló es que existe un alto nivel de participación de los apoderados en ciertas actividades culturales que fomentan determinadas festividades y tradiciones características de la población de la región y en el resto de países vecinos: "Los padres y apoderados participan y colaboran en las actividades realizadas en el colegio, como la celebridad de La Cruz de Mayo, el Machaq Mara, y la gala artística de Fiestas Patrias, entre otras. Muchos aportan materialmente, como también prestando sus servicios. Por ejemplo, en la celebridad de La Cruz de Mayo hay apoderados que se ponen con los ingredientes para realizar un picante y otros con la banda de bronce. Existe un compromiso principalmente de parte de los apoderados que pertenecen al pueblo y al valle, pues estas celebridades son parte de sus tradiciones" (DH-LR).

Este último testimonio es significativo por varias cosas. Por una parte, evidencia que algunos establecimientos educacionales ubicados en zonas rurales y con alta presencia de estudiantes con raigambre aymara han ido incorporando una serie de celebraciones características de la población aymara y que poseen una raigambre importante en los valles de Arica. Por otra parte, llama la atención que otros docentes, apoderados o alumnos no hayan mencionado estas actividades, lo que puede evidenciar que para muchos de ellos éstas no son consideradas formalmente como instancias que promueven la integración cultural de los estudiantes de origen extranjero. Finalmente, es importante destacar que diversos apoderados plantearon que una de las estrategias que podrían implementar los establecimientos en el futuro para fomentar la integración de estudiantes y apoderados de origen extranjero, es celebrar festividades propias de cada país (fiestas patrias, efemérides, etc.) o que sean comunes, donde se 
pueda compartir un poco de historia del país vecino, danzas, comidas y diversas tradiciones, fomentando con ello una integración sociocultural real.

\section{Integración de pares y docentes}

A lo largo de las entrevistas hemos podido apreciar que uno de los ámbitos donde se desarrolla de manera más efectiva la integración sociocultural de los alumnos de origen extranjero, es en los espacios de interacción y socialización con sus compañeros de curso o amigos (pares) dentro del establecimiento escolar.

El primer hecho general que debemos destacar es que la mayoría de los entrevistados (especialmente los alumnos y apoderados) señala que al principio del proceso de sociabilización de los estudiantes de origen extranjero con sus pares de origen chileno, existen algunas limitaciones en la adaptación. Sin embargo, en este punto hay una clara diferencia entre establecimientos urbanos y rurales.

En los casos urbanos, tiende a ser más difícil la integración, entre otras cosas porque los alumnos extranjeros son minoritarios, los establecimientos no suelen tener una dinámica de integración cultural tan explícita al respecto y, también, porque la mayoría de los entrevistados señaló que el perfil de los estudiantes urbanos (más "inquietos", "irrespetuosos”, etc.) tendía a dificultar en cierta medida este proceso de integración. En los casos rurales, la integración es descrita como más "fácil" y "natural", entre otras cosas porque los alumnos de origen andino (chilenos, peruanos o bolivianos) representan un porcentaje mucho mayor entre los estudiantes, ${ }^{9}$ estableciéndose una especie de integración étnica al respecto. Además, los establecimientos poseen algunas dinámicas (sobre todo implícitas) más acordes con este fenómeno de integración sociocultural. Y finalmente, porque el perfil de los estudiantes rurales (descritos como más "tranquilos", "respetuosos", etc.) tendería a facilitar la recepción de normas y los procesos de integración. Este proceso de adaptación inicial es descrito por un docente de un liceo rural:

9 Por ejemplo, en uno de los liceos rurales "existen 343 alumnos extranjeros (el 52,8\% del total de la matrícula del liceo), de los cuales 232 son bolivianos, 110 peruanos y un brasileño" (D-LR).
"Como en todos lados cuando llega un alumno nuevo existe primero una etapa de adaptación, la cual se demora unas pocas semanas para que pueda desenvolverse con todo el curso... En el pasar de las semanas el alumno nuevo es uno más del grupo. Por lo general los cursos son muy unidos" (D-LR).

Según esta lógica los alumnos de origen extranjero en las escuelas rurales finalmente "se adaptan bien a la dinámica del colegio", donde "los extranjeros, por lo general, se integran también rápidamente a sus compañeros, que los aceptan de buena manera debido al gran número de ellos con que conviven día a día" (D-LR). Si bien este docente señala la ya mencionada dificultad de adaptación inicial a la que se ven enfrentados los alumnos de origen extranjero, destaca que, en el caso de su establecimiento (liceo rural), existe cierta normalización de estos eventos, pues se producen de manera recurrente, lo cual ha facilitado la integración de estos alumnos.

Más allá de las dificultades de adaptación inicial que puedan presentarse, especialmente en los contextos urbanos, una parte importante de los entrevistados tiende a destacar en sus discursos que la integración de alumnos de origen extranjero no es un problema que esté afectando actualmente a los establecimientos educacionales. Sostienen que existe una buena adaptación de parte de los estudiantes, sobre todo en contextos rurales, donde la presencia de estudiantes de origen extranjero es mucho mayor que en la zona urbana:

"Para los alumnos chilenos, el hecho que llegue un alumno nuevo extranjero no le es nada novedoso, ya que están acostumbrados a relacionarse con estos alumnos y se integran rápidamente al curso [...]. En los cursos, los extranjeros, por lo general, se integran también rápidamente a sus compañeros, que los aceptan de buena manera, debido al gran número de extranjeros con que conviven día a día [...] Los alumnos de origen extranjero se adaptan bien a la dinámica del colegio, pues en este establecimiento se tiene como prioridad la integración de estos alumnos" (D-LR).

Como señaló otra docente, este fenómeno se ve apoyado por la política del establecimiento. Si bien, como comenta una docente directiva: "Con el tiempo puede que se generen algunas bromas y apodos, 
dependiendo de las circunstancias y características del joven en cuestión, ya sea por su aspecto físico o por su forma de hablar". Es que dentro del establecimiento las conductas discriminatorias son consideradas como una falta muy grave, por lo que finalmente no suelen sostenerse en el tiempo.

Es importante señalar que tanto docentes como apoderados establecen una diferencia importante entre los estudiantes más pequeños de las escuelas y aquellos adolescentes que asisten a los liceos, pues los primeros tienden a integrar de manera más rápida a los estudiantes de origen extranjero que los segundos. Así, el preguntarle a una docente qué hacían los estudiantes de su escuela cuando llegaba un alumno de origen extranjero a su clase, destacó que "no se dan cuenta... no tienen esa conciencia de discriminar, de segregar... para ellos es un niño nomás" (DM-ER).

Entre los adolescentes que asisten a los liceos, los que pertenecen a cursos mayores (tercero y cuarto medio) suelen ser bastante integradores, pues las relaciones sociales con los estudiantes de origen extranjero y los lazos de amistad están más establecidos; mientras que en los cursos inferiores (primero y segundo medio), los alumnos suelen ser "más inmaduros, lo que los hace más proclives a bromear y molestar a compañeros, situación en la que se puede ver afectado un alumno extranjero" (UTP-LR).

Este punto destacado por los docentes evidencia la existencia de un entorno educacional que tiende a favorecer la integración en el largo plazo. Además, muestra que las formas de diferenciación y discriminación sociocultural se van presentando paulatinamente a medida que los niños se siguen desarrollando y continúan socializándose en un entorno que tiende a reproducir muchas de las diferencia socioculturales entre personas de diversos orígenes étnicos y nacionales durante los primeros años de estudios secundarios, pero que finalmente logran disminuir (o ser invisibilizadas) en el largo plazo.

Es importante destacar que la mayoría de los entrevistados sostiene que no hacen (o no tienden a hacer) diferencias entre los estudiantes de origen extranjero y los de origen nacional, señalando su supuesta igualdad como estudiantes. En el caso de los establecimientos rurales, se agrega que las diferencias entre ambos tipos de estudiantes son casi inexistentes o imperceptibles. De hecho, al preguntarle a una docente cómo identificaba a aquellos alumnos que son de origen extranjero del resto de estudiantes, señaló: "La gran mayoría de los alumnos de este liceo son aymaras y afrodescendientes, por lo que el aspecto físico no identifica su origen extranjero sino, más bien, su forma de hablar. Por lo general no existen grupos diferenciados... En este liceo no existen grupos netamente de alumnos pertenecientes a una misma nacionalidad. Los alumnos, sin importar nacionalidad ni etnia, se relacionan muy bien entre si” (D-LR).

Otra docente señaló que uno de los pocos aspectos que permite su diferenciación es simplemente la fonética y acento al hablar, especialmente en el caso de los estudiantes de origen bolivianos: "Por ejemplo, los niños bolivianos marcan mucho la erre, son erres diferente a Chile... solo eso" (DM-ER). Sin embargo, este último aspecto ha sido también objeto de diferenciaciones, bromas y burlas internas entre los estudiantes, como han señalado algunos testimonios; y donde la integración pasaría, entre otras cosas, por una normalización en la forma de hablar cotidiano. Pero después que el lenguaje se "normaliza", tienden a minimizarse aún más estas diferencias entre los estudiantes. Como señaló un alumno que recibía burlas de diversos compañeros. Luego de que cambió su acento, aseguró: "Ya no me molestan tanto" (EH-LR-P). No obstante, otro docente declaró que la diferenciación entre alumnos se convierte muchas veces en imposible, pues ni siquiera por el lenguaje se logra distinguirlos: "Es que se juntan todos con todos, no permite notar el acento; de hecho, yo tenía niños chilenos que pensaba que eran chilenos y cuando hago la ficha de matrícula identifico que son bolivianos y no podía creerlo. Yo así como 'qué raro' porque pasan colados" (DM, ER).

\section{Integración e indistinción étnica}

Uno de los aspectos más interesantes que pudimos apreciar en el análisis de los datos recolectados es la importancia de la dimensión nacional y étnica en los procesos de adaptación e integración de estudiantes de origen extranjero en los establecimientos. 
En primer lugar, si bien la mayoría de los entrevistados, especialmente docentes y alumnos, suelen destacar que los estudiantes de origen extranjero establecen relaciones con todos sus compañeros de curso, indistintamente de su origen nacional o nacionalidad, en muchos casos gran parte de los compañeros del círculo cercano o amigos de los estudiantes de origen extranjero suelen ser también extranjeros. Sobre todo durante el primer período de llegada y adaptación de los alumnos a los establecimientos y, especialmente, en aquellos centros donde los estudiantes extranjeros son una minoría, como en la urbe. Así, es posible apreciar un efecto de integración social asociado al origen nacional, pues son los connacionales o coterráneos quienes facilitan la inmersión del alumno en el colegio o liceo: "Me he dado cuenta que, en un principio, los alumnos extranjeros que se incorporan al liceo, primero buscan juntarse con los alumnos de su misma nacionalidad, quizás pensando en que van a ser excluidos por sus compañeros chilenos" (D-LR).

El círculo de connacionales no solo parece ofrecer un espacio más reducido de lazos sociales iniciales, sino también un ámbito conocido donde se brinda una potencial protección ante un eventual rechazo de los estudiantes de otros orígenes. Esta situación puede verse reforzada por los posibles lazos que pueden tener algunos apoderados de origen extranjero, tanto en el ámbito educacional como fuera de él, estableciéndose así una red de cooperación recíproca entre connacionales. No obstante, esta situación puede cambiar con el tiempo, una vez que los estudiantes de origen extranjero o nacional hayan establecido nuevas pautas de interacción y socialización que reconfiguran sus lazos iniciales, tanto en el ámbito rural como urbano.

En segundo lugar, también existe un efecto de integración mucho más amplio relacionado con el origen étnico común de estudiantes chilenos, peruanos y bolivianos. Esto se manifiesta especialmente en los establecimientos ubicados en la zona rural (los valles), pues son éstos los que reciben a la mayor cantidad de estudiantes peruanos y bolivianos (como se puede observar en la Tabla 1). Muchos de estos estudiantes han llegado a estas zonas debido a la migración y, especialmente, debido a las labores agrícolas que realizan sus padres en la zona. Estas familias y sus hijos son mayoritariamente de origen aymara, como también lo son muchos de los estudiantes chilenos que habitan en la zona de los valles de Arica.

En un contexto donde existe una gran migración peruana y boliviana, tanto de primera como de segunda generación, y donde gran parte de los estudiantes son de origen aymara (extranjeros o no), la pertenencia étnica se transforma en un identificador mayoritario que se superpone a las identificaciones nacionales específicas. Esto afectaría directamente a la integración de los estudiantes de origen extranjero en los establecimientos: "Los niños se integran bien, yo pienso que se integran bien, porque aquí hay un gran porcentaje de niños que son peruanos y niños que son bolivianos, porque aquí, aunque sean chilenos, muchos, la gran mayoría tiene descendencia aymara, si tú ves, la lista de los libros, de los cursos, por los apellidos te das cuenta de que éstos son, tienen, la gran mayoría, es como un $85 \%$ del colegio, tienen apellido aymara, pero ellos se integran bien y no existe como una segregación en que tú eres peruano o tú eres... no, yo por lo menos que llevo cinco años acá no lo he visto" (DM-ER).

En este sentido, la evidencia empírica da cuenta de uno de los principales hallazgos de este estudio: son los mismos actores del sistema educativo, en este caso los estudiantes de origen extranjero, quienes desarrollan de manera emergente las estrategias y mecanismos para lograr una buena integración y adaptación al contexto educacional, utilizando para ello aspectos de la dimensión cultural-étnica para facilitar este proceso. Como señaló claramente una de las entrevistadas, jefa de la unidad técnico-pedagógica de un liceo rural: "Generalmente [los alumnos] desarrollan sus propios mecanismos, tratando de adaptarse al nuevo ambiente, estableciendo lazos de amistad que les permitan ser parte de un grupo. Particularmente, se juntan con estudiantes de origen indígena, que son numerosos en la media, especialmente los alumnos peruanos y bolivianos, ya que, al parecer, comparten más elementos en común, por ejemplo gustos musicales, pasatiempos, etc." (UTP-LR).

En este sentido, no solo podemos señalar que existe una integración de carácter étnica, sino que también se da una especie de invisibilización identitaria 
como estrategia de adaptación de los alumnos: "Los estudiantes extranjeros se tratan de integrar al curso, invisibilizando un poco su origen" (UTP-LR). De esta forma, la dimensión étnica juega un rol clave que nos permite comprender cómo funcionan los procesos de integración sociocultural dentro del ámbito educacional en la región.

\section{Dilemas de la integración}

Uno de los aspectos que limita la adecuada integración inicial de los estudiantes de origen extranjero, son sus potenciales problemas educativos. Ante esta situación, es necesario realizar una serie de actividades en el marco de un programa de integración que les permita nivelar sus conocimientos, aprendizajes y habilidades: "Uno de los problemas que presentan los alumnos extranjeros recién incorporados es la baja comprensión lectora que poseen. Además, hay que tomar en cuenta que algunos no saben leer de manera fluida y están cursando la educación media... Los alumnos que llegan provenientes de otros países, tienen que pasar por un trámite de validación de estudios previos, que permite conocer el nivel de curso que tienen y al que deben de ser incorporados" (D-LR).

Por una parte, llama la atención el hincapié que hacen los profesores en esta dimensión educativa a la hora de describir los problemas de integración de los alumnos. Por otra, evidencia también cómo la dimensión educativa juega un rol esencial para los docentes y alumnos a la hora de adaptarse al contexto local. Es interesante apreciar también de qué modo las principales limitaciones señaladas por muchos profesores están vinculadas concretamente al rendimiento en el plano del lenguaje y los contenidos de historia. Ambos ámbitos están estrechamente relacionados tanto con el nivel educacional y la formación previa recibida en el sistema educativo de origen como con el nivel educativo de la familia. Esto se ve reflejado en una de las entrevistas a una apoderada de nacionalidad peruana de una de las escuelas escogidas: "Claro, es que allá en Perú es completamente separado lo que es historia y lo que es geografía, pero sí creo que definitivamente historia bastante, porque como recién le comentaba a mi hija les había pasado unas hojas para resolver y ella andaba preocupada porque me dijo 'mamá no he resuelto casi nada', solamente lo poco que yo sabía, y yo le digo, pero qué te preguntaban... 'de Arturo Prat, de personas que no conozco'. Entonces me dijo 'creo que voy a tener problemas en ese ramo'. Y yo le dije bueno, no te preocupes, poco a poco vas a ir investigando en internet, tienes que meterte más a investigar porque actualmente estamos en Chile y actualmente tienes que aprender la historia que es aquí en Chile, y como que ya me di cuenta que iba a tener problemas en ese ramo" (AP-EA).

También existen docentes que trabajan en contextos donde hay gran presencia de estudiantes de origen extranjero aymara y han debido adaptarse a las dinámicas de interacción de estos estudiantes, no solo recurriendo a los programas formales de nivelación, sino también adaptando contenidos y su práctica docente: "En clase, he tenido que aprender a adaptarme a la forma de ser tan particular que tienen los niños aymaras, principalmente bolivianos y peruanos (el tuteo, la calma, la poca comprensión, y la fácil distracción). También, he tenido que trabajar y preparar materiales en donde se tenga que dar ejemplos cercanos y cotidianos para ellos" (DH-LR).

Más allá de estos problemas que suelen estar asociados al rendimiento estrictamente académico, existen otros problemas de integración sociocultural relacionados con la identificación nacional o étnica de los alumnos de origen extranjero. Pese a que, en general, se señala que la discriminación hacia alumnos de origen extranjero es minoritaria en los establecimientos, se asume que el fenómeno existe, en tanto la educación y los establecimientos forman parte de una sociedad que tiende a estigmatizar a las personas que provienen de los países andinos vecinos: "La verdad es que, lamentablemente el trato diferente siempre es negativo, tomando en cuenta que los grupos de extranjeros son en su mayoría peruanos, bolivianos y colombianos. Nuestra sociedad, lamentablemente, mira muy en menos a estos países y, no siendo la excepción en sus casas, los alumnos ya traen consigo este espíritu discriminativo; por ello, es fundamental el rol del docente dentro de este proceso de conocer" (D-LR).

Esta situación es mucho más patente en el contexto de los establecimientos ubicados en los radios urbanos, y dentro de ellos, de manera más intensa 
(aunque no mayor en cantidad) en aquellos que imparten educación media, especialmente en los primeros cursos (primero y segundo medio). En los establecimientos rurales, en general, los entrevistados señalan que casi no existen casos de discriminación. De hecho, uno de los aspectos más interesantes destacados por docentes y apoderados es que existe una enorme diferencia al respecto entre los establecimientos urbanos y rurales. Los primeros son vistos como entornos mucho más competitivos, violentos, y donde se producen más casos y formas de discriminación hacia los estudiantes y personas de origen extranjero, especialmente peruanos, bolivianos y colombianos. Los segundos son vistos como entornos mucho más tranquilos, con un ambiente más relajado, y donde los casos de discriminación hacia estos estudiantes son menores. Esta diferencia entre los establecimientos rurales y urbanos es apreciada también por los apoderados: "Este colegio no es tan discriminativo como los colegios en Arica, los liceos. Acá, la mayoría de los que viven en el valle son extranjeros, así que se adaptan... No como en Arica, en Arica sí que hay diferencia... Hay discriminación en cuanto a los nińos que son extranjeros: se burlan de ellos como se visten y como hablan, sí se ve, yo he visto... Acá la mayoría de la gente que vive acá en el valle, es extranjera... Acá los reciben como cualquier niño 'nomás', ya sean chilenos o extranjeros... Acá van todos tranquilos los nińos, pensando que en Arica es lo mismo que acá. Yo creo que llegando allá tiene que salvarse el que es más vivo, el que es más popular. El que es más tímido, es discriminado, le hacen bullying. Yo le explico a veces: no hay que ser ni tan vivo ni tan tonto" (AM-ER-CH).

\section{Diálogo y convivencia}

En general, los apoderados y los docentes (especialmente estos últimos) señalan que el equipo de profesores y directivos de las escuelas y liceos analizados se caracterizan por no realizar ni fomentar ningún tipo de diferencia entre los estudiantes y apoderados de origen extranjero y los de origen chileno; más bien, apoyan la integración de los estudiantes. Sin embargo, existe cierto consenso entre los docentes a la hora de afirmar que no existen políticas formales de la institución para acoger e integrar a los estudiantes y apoderados de origen extranjero. Como señaló una de las docentes, esto aparece como una tarea que simplemente se debe realizar: "Nosotros tenemos el deber de recibirlos" (DM-LU). Pero nadie sabe exactamente cómo realizar exitosamente esta labor. Tampoco suelen desarrollar alguna estrategia planificada específica al respecto, más allá de las que realizan con la mayoría de los estudiantes nuevos cuando ingresan a un curso.

Dentro de este contexto se han presentado situaciones conflictivas o problemáticas, donde muchas veces se han manifestado formas de discriminación entre los estudiantes. Los profesores enfatizan nuevamente que no poseen ninguna normativa formal y explícita sobre qué deben hacer al respecto, menos aún cuando esta situación involucra temas de diferencias culturales o étnicas. Como ocurre con el rol que han jugado los pares en la integración de los estudiantes en los establecimientos, en este caso son los docentes quienes han desarrollado (o no) sus propios mecanismos en función de la situación, la problemática, sus herramientas y capacidades.

En general, se aprecia que una de las maneras predilectas utilizadas por diversos docentes para enfrentar estas problemáticas es la utilización del diálogo entre los estudiantes en conflicto, así como también con el profesor, otras personas del establecimiento (directivos, jefe de unidad técnico-pedagógica, psicopedagogo, psicólogo) y con los mismos apoderados de los alumnos involucrados. También afirman que las mismas normas de convivencia que se establecen en la sala de clases y en el establecimiento son utilizadas a la hora de resolver conflictos o problemas entre alumnos. Como señaló una docente, ante la emergencia de problemas: "Nosotros ponemos mucho énfasis en las normas de convivencia, en el diálogo. Se conversan los problemas entre los compañeros, se piden disculpa, se hace ver en qué se equivocaron, por qué no debieron haber actuado en esa manera, pero no hay casos graves de comportamiento" (DM-ER).

En esta misma línea, un jefe de UTP nos indicó: "Siempre es efectivo conversar con los estudiantes para hacerles entender su comportamiento y encontrar soluciones en conjunto, frente a alguna situación de conflicto. También es importante estar atento a las relaciones que se generan en el aula, entre los compañeros, para detectar cualquier situación de discrimi- 
nación o burlas hacia compañeros extranjeros; si éstas son persistentes y continuas pueden ser consideradas como bullying. Lo peor es hacer la vista gorda frente a situaciones que, a veces, uno observa que ocurren en el aula; es mejor hablar con los alumnos y aclarar la situación. También es importante comunicar al apoderado situaciones que puedan estar ocurriendo y que afecten al estudiante" (UTP-LR).

\section{Curriculum oculto}

Otro aspecto relevante que emergió de la recolección de datos es el testimonio del directivo de un liceo, quien señaló que si bien los docentes tienden a tratar de igual manera a todos los estudiantes y apoderados, sin establecer diferencias explícitas entre quienes son de origen extranjero y quienes no lo son, igualmente puede apreciarse un trato algo diferenciado: "De forma explícita, no pareciera haber un trato diferente hacia los alumnos y apoderados extranjeros, pero de manera implícita, los profesores manejan cierto 'currículo oculto' hacia determinados grupos: por ejemplo, hacia los estudiantes y apoderados bolivianos que, por tener un nivel cultural más bajo y una actitud más despreocupada por los estudios, son vistos como más ausentes que los nacionales" (UTP-LR).

Diversos intelectuales de la educación, particularmente de la línea de la educación intercultural, han analizado el fenómeno del currículum oculto o tradicional. Según Magendzo (1986, p. 9) la existencia de discursos centralizados, uniformes y etnocéntricos habría conducido a discriminaciones en el currículum. De esta manera, "la cultura de los indígenas, la mujer, los campesinos, los pobladores, los pobres y muchos otros grupos marginados no han tenido espacio en los saberes que se transmiten. Existe, por así decirlo, una incapacidad de reconocer al otro". Así, si bien podríamos señalar que una diferenciación en el trato puede obedecer a la necesidad de establecer una forma específica de ayuda u apoyo a los estudiantes y apoderados de origen extranjero, también puede significar que esta diferencia de trato simboliza la existencia de una cierta jerarquía entre los estudiantes y apoderados de origen extranjero y los chilenos, debido a las (supuestas) diferencias de capital cultural apreciadas por los docentes. Finalmente el currículo oculto se manifiesta asimilando a los estudiantes inmigrantes a una realidad nacionalista chilena. ${ }^{10}$

Una vez más vemos que ante la inexistencia de mecanismos formales que permitan tematizar fenómenos como el mencionado, se terminan imponiendo estrategias contextuales que reproducen una serie de prejuicios y estigmatizaciones étnicas, culturales, nacionales y educacionales sobre las personas de origen extranjero, no instando al desarrollo de una integración sociocultural exitosa.

\section{Integración institucional (políticas y establecimientos)}

Como ha quedado en evidencia, uno de los principales hallazgos empíricos obtenidos durante el desarrollo de este estudio es que casi la totalidad de entrevistados plantea el desconocimiento o la inexistencia de políticas formales y mecanismos de integración específicos, destinados a lograr una mayor y mejor integración sociocultural de los alumnos de origen extranjero que cada año ingresan a las aulas de sus establecimientos. Como enfatiza un docente de una escuela urbana: "No hay políticas para integrar a esos nińos, solamente el apoyo que da el asistente social a veces para hacer trámites, sacar el carné, esas cosas. Pero una política de integrarlos no hay" (D-EA). Por otra parte, como subraya una de las jefas de la unidad técnico-pedagógica de uno de los establecimientos analizados, ante la creciente demanda e ingreso de estudiantes de origen extranjero en su establecimiento, "falta una política de acogida por parte del colegio, que les permita conocer la cultura escolar de la cual serán parte. Falta nivelación de estudios" (UTP-LR).

10 Según Poblete, "nuestro país ha vivido históricamente bajo la ilusión de la homogeneidad cultural; marginados los indígenas y grupos populares de la vida social y política, el Estado nacional creyó resuelta la problemática que generaba la presencia de culturas que no calzaban con la imagen de un país moderno. Existe un vacío en las representaciones de los profesores de un enfoque educativo intercultural, que debiera fortalecer las identidades nacionales y culturales de la alteridad, para favorecer en la praxis que los estudiantes den significados propios de su vida cotidiana y puedan desempeñarse de forma eficiente en diferentes contextos" (2009, p. 183). 
Respecto a las políticas de integración de las familias, tanto de estudiantes nacionales como de origen extranjero, la misma entrevistada señaló que las únicas formas de integración que existen son indirectas: "No existen de forma explícita, pero sí se invita a todos los apoderados a participar en espacios donde puedan expresar sus ideas o preocupaciones" (UTPLR). Concretamente, estos espacios están limitados (en gran medida) a las reuniones mensuales de apoderados dentro de cada curso y alguna otra actividad cultural o educativa desarrollada en el establecimiento donde se invita a los apoderados a participar, por lo que los entrevistados advierten las limitaciones de esta política.

Sin embargo, dentro del universo de entrevistados, existe un caso específico que señala la existencia de políticas explícitas de integración, tanto para estudiantes extranjeros como para su familia. Un docente del liceo rural señala que su establecimiento "ya realiza actividades para integrar nuevos alumnos extranjeros. De hecho, se ha realizado promoción y entregado información en el valle y alrededores, indicando la visión y misión del liceo", aunque estas medidas son más bien generales. Además, agrega que en el establecimiento se ha llevado a cabo el programa Ciudadano Global, a través del cual se ha brindado atención personalizada a los alumnos y apoderados en ámbitos sociales, legales, psicológicos y laborales, sobre todo a los alumnos extranjeros que poseen una situación de vulnerabilidad. Además de ofrecer la posibilidad de "regular los papeles de los alumnos cuando sus padres se encuentren de manera indocumentada en el país y evitar que sea un impedimento para que el hijo pueda estudiar" (D-LR). Asegura que esta última medida ha permitido que la matrícula del establecimiento haya aumentado en 100 nuevos alumnos, argumentando, a su vez, que esto refleja lo positivo del liceo, que "se caracteriza por ser muy integrador, pues conviven con respeto alumnos chilenos, bolivianos y peruanos, entre los cuales se encuentra un alto número de alumnos aymaras (aproximadamente el $70 \%$ del total de la matrícula) y afrodescendientes" (D-LR).

Asimismo, este fue el único docente que ha señalado y destacado la gestión y desarrollo de una serie de actividades culturales propias de la tradición aymara, como la celebración de festividades y ritualidad tra- dicionales, la implementación de la lengua aymara y su inclusión formal en el establecimiento: "Bolivia, Perú y el norte de Chile tienen algo en común: la cultura aymara. En el liceo se desarrollan diversas actividades culturales de esta etnia a la que pertenecen la gran mayoría de los alumnos. Lo evidencian actividades como la celebración del Machaq Mara y La Cruz de Mayo, además de la implementación de la lengua aymara en los niveles prebásicos y como asignatura obligatoria desde primero a cuarto básico, siendo además utilizada en actos cívicos para los saludos y agradecimientos" (D-LR).

En este sentido, el desarrollo de actividades distintivas de la cultura aymara no solo es visto como dinámicas que apuntan a la valorización del patrimonio cultural de esta etnia presente en nuestra región, sino también como mecanismos socioculturales que pueden permitir una integración real entre los estudiantes de origen extranjero, en tanto la mayoría comparte algún vínculo con esta etnia.

\section{Evaluación de docentes y politicas públicas}

A la hora de evaluar la existencia de políticas concretas destinadas a fomentar la integración de alumnos y docentes de origen extranjero, existen matices entre las apreciaciones de los entrevistados.

En primer lugar, la mayoría de los apoderados, así como también algunos docentes y alumnos, señalan que la inexistencia de políticas o estrategias concretas sobre la integración de estudiantes de origen migrantes es una limitación importante que poseen los establecimientos educacionales, agregando que debieran desarrollarse prontamente para poder afrontar exitosamente el nuevo escenario multicultural que se está produciendo en los centros educativos de la zona dada y que se relaciona con la creciente inmigración. A la hora de consultar directamente por estas políticas, una jefe de UTP dijo: "Pienso que son insuficientes, falta informar más a los docentes sobre el tema de los estudiantes inmigrantes y desarrollar estrategias más definidas para estos grupos de alumnos, aunque sean un número minoritario al interior de la comunidad educativa" (UTP-LR).

En segundo lugar, si bien la mayoría de los entrevistados señalaron que no existen políticas de integración 
específicas para los alumnos y familiares de origen extranjero en los establecimientos, consideran que muchas de éstas serían innecesarias para el caso de los estudiantes, pues, aparentemente, la inmensa mayoría de ellos no presenta mayores problemas de integración en los colegios y liceos, sobre todo en los contextos rurales, donde se manifiesta una mayor integración cultural y educativa. La emergencia de mecanismos de socialización desarrollados por los propios estudiantes extranjeros y sus compañeros de clase, unidos a las estrategias concretas y puntuales desplegadas por los docentes en los establecimientos, parecieran bastar en la mayoría de los casos.

En tercer lugar, tenemos una opinión bastante minoritaria que señala que las políticas institucionales son adecuadas y suficientes para afrontar el fenómeno de la integración de los estudiantes y familiares de origen extranjero. Así, uno de los docentes de un liceo rural señaló que el desarrollo de programas como Ciudadano Global, ha permitido la integración de estos alumnos, además de demostrar el interés y preocupación del liceo por ellos. Si bien se trata solo de un docente y de un establecimiento en particular, es importante considerar la caracterización que realiza de las políticas que ha considerado como exitosas.

No debemos dejar de subrayar que muchos docentes, apoderados y alumnos asocian el fenómeno de la integración sociocultural con la integración estrictamente educativa (aprendizajes y contenidos) que puedan recibir los alumnos con mayores dificultades al respecto, tanto de origen extranjero como nacionales: "El hecho de realizar programas como el de reforzamiento ayuda a que estos alumnos refuercen las habilidades que no dominan como corresponde, debido al diferente nivel de contenidos con los de sus países de origen. En las evaluaciones, se encuentran mejor preparados por haber desarrollado los programas que se consideran. De esta manera, los alumnos extranjeros pueden llegar a dominar las mismas habilidades que sus compańeros chilenos, evitando la discriminación por parte de éstos por el común bajo dominio de habilidades que poseen $y$ que no están acorde con el nivel de educación [curso] en el cual se encuentran" (D-LR).

Por otro lado, algunos entrevistados (sobre todo apoderados y docentes) especificaron que uno de los ámbitos concretos donde debieran desarrollarse nuevas estrategias es en el plano docente, pues, actualmente, existen importantes limitaciones para desarrollarlas vinculadas a las obligaciones de cobertura curricular que posee cada una de las asignaturas. De hecho, se infiere que existe una crítica a la estructuración formal de los currículos educativos al respecto: "Yo creo que se podría hacer más, ya que cada profesor tiene su propio discurso y forma de abordar su clase. Sería pertinente involucrar al equipo de gestión del colegio en el desarrollo de una estrategia común en la escuela [...] Estoy preparada, pero las obligaciones de cobertura curricular de cada asignatura limitan la oportunidad para desarrollar trabajos de esta índole" (UTP-LR).

Más allá de estas limitaciones, la gran mayoría de los entrevistados, tanto en el contexto rural como urbano, realizaron una asociación directa y primordial entre las estrategias de integración y la importancia de la labor docente para lograr esta tarea en los establecimientos. Tanto quienes son críticos de los profesores como quienes evalúan positivamente su actuar, tienden a depositar mayores expectativas en los docentes que en el establecimiento escolar o en las políticas educacionales, por lo que existe una (sobre)valoración de las capacidades y la importancia del docente en este ámbito. Como señaló uno de los docentes de manera testimonial: "Yo considero que el docente juega un papel fundamental en la integración y respeto hacia los alumnos extranjeros, principalmente porque son alumnos que necesitan la misma atención y derechos que los chilenos, ya que las nacionalidades no deben ser ningún factor de discriminación y rechazo, ni para las evaluaciones, ni mucho menos para el trato social. El profesorado, por tal motivo, debe dar el ejemplo para que sus alumnos piensen de la misma manera y tengan que aceptar a sus compańeros extranjeros. El profesor debe respetar las costumbres culturales de todos sus alumnos y hacer que ellos se desenvuelvan en un ambiente cómodo y óptimo para desarrollar la clase" (D-LR).

\section{Aspiraciones en la integración: docentes y apoderados}

Las aspiraciones que poseen los docentes y apoderados con respecto a la integración de sus alumnos y/o pupilos en el terreno educacional y prontamente 
laboral son un aspecto importante a considerar. Estas aspiraciones están enfocadas en que los estudiantes posean un mejor porvenir educacional y que los lleve al éxito profesional.

Por una parte, tanto docentes como apoderados esperan que los recintos educacionales presenten más propuestas efectivas de integración, permitiendo que tanto extranjeros como chilenos convivan y compartan a su vez sus experiencias, como por ejemplo "talleres de interculturalidad" (D-LR), y así cultivar una convivencia mucho más cercana entre los apoderados y los docentes. Por otra parte, ambos actores esperan que los estudiantes tengan un futuro exitoso en el aspecto educacional y laboral. En este último punto, un docente nos indica algo fundamental: "Bueno, ellos [los apoderados] siempre van a esperar que sus niños sean más que ellos. Además, los nińos tampoco quieren ser igual que sus padres, ellos no quieren estar trabajando, tirando pala, trabajar la tierra. Y, por supuesto, ellos quieren que sus hijos, en algunos casos, lleguen a la universidad y, en otro casos, que se vayan a un instituto técnico, que tengan un título para que vayan al liceo y que tenga su título, que sean algo" (D-G8).

Esta declaración se confirma con el siguiente comentario de una apoderada agricultora: "Como mamá sin estudios, espero ver a mis hijos felices, haciendo lo que ellos quieran hacer. Si estudian, mucho mejor para que tengan su profesión y no trabajen como yo. Hasta el momento, mis dos hijos mayores son técnicos profesionales (uno en minería y la otra en enfermería) y por eso me siento contenta” (AP-LR).

\section{Consideraciones finales}

A partir del análisis realizado, hemos podido advertir cómo los distintos agentes de la comunidad escolar han desarrollado diversas estrategias y prácticas para lograr la integración sociocultural de los estudiantes de origen extranjero en el sistema educativo local, ante la casi inexistencia de mecanismos formales educativos al respecto. En concreto, hemos podido advertir la presencia de mecanismos de integración a nivel personal-familiar, social e institucional.
En primer lugar, apreciamos que una parte importante de estudiantes y apoderados de origen extranjero (especialmente peruanos) ha señalado que durante el proceso de inserción inicial en la sociedad y en el sistema educativo chileno tuvieron ciertas dificultades. Sin embargo, en el mediano plazo, la mayoría de los estudiantes logró adaptarse con relativo éxito a las escuelas y liceos donde asistían, mientras que los padres alcanzaron una integración (sobre todo) en el plano económico-laboral en la sociedad local. Este proceso se vio facilitado por la existencia y desarrollo contextual de procesos y mecanismos de integración sociocultural de carácter familiar e individual. En este punto, se destaca la existencia de familias residentes que han llegado a Chile en busca de mejores condiciones socioeconómicas, y cuyo principal mecanismo de inserción escolar propiciada por los padres a sus hijos es la adaptación a las normas locales del sistema educativo, pese al bajo capital cultural que suelen poseer estas familias (según diversos docentes). Las prácticas individuales de los alumnos suelen estar influidas y orientadas por esta formación familiar.

En segundo lugar, este proceso individual y familiar se ha visto facilitado por la existencia de mecanismos informales que se despliegan en la escuela por parte de los pares (compañeros de estudio) y determinados docentes. La convivencia cotidiana de los alumnos de origen extranjero con sus connacionales o con alumnos de origen aymara (en primer lugar) y luego con el resto de estudiantes de origen chileno (sean o no aymaras), unida a algunas estrategias específicas que desarrollan docentes ante la presencia de alumnos extranjeros de manera contextual y poco planificada, han permitido generar una relativa integración y adaptación de estos estudiantes al ámbito escolar, no exenta de dificultades y problemáticas, como la presencia de ciertos casos específicos de estigmatización.

En tercer lugar, también hemos podido apreciar que la mayoría de alumnos (migrantes o no), apoderados y docentes desconocen la existencia de algún programa formal impulsado por el Ministerio de Educación orientado a desarrollar mecanismos de integración sociocultural de alumnos y familiares de origen migrante en la comunidad escolar. Además, una parte importante de los docentes señala 
que simplemente no existen planes ni programas que tematicen concretamente el fenómeno de los estudiantes inmigrantes y su inserción en el sistema educativo. Esto se aprecia en todas las instituciones educativas analizadas (colegios y liceos, urbanos y rurales). En este escenario, es importante subrayar que para la mayoría de docentes, la integración es vista primeramente como una necesaria nivelación en el ámbito educativo formal, que conllevaría posteriormente a una mayor integración educativa. En cualquier caso, los agentes de la comunidad escolar (alumnos, apoderados, docentes y directivos) tienen mayores expectativas en los docentes que en las políticas institucionales a la hora de lograr una integración sociocultural exitosa de los estudiantes de origen extranjero en el sistema educativo.

En cuarto lugar, basados en nuestra evidencia empírica queremos sugerir a la política pública que es necesario fomentar la creación de espacios donde se puedan desarrollar dinámicas de integración sociocultural en horarios flexibles para los padres trabajadores. Se ha sugerido especialmente el fomento de actividades ligadas al desarrollo de conocimientos prácticos sobre la integración cultural entre los países fronterizos con Chile, a través de expresiones como la música, las danzas, la gastronomía, las celebraciones de festividades y efemérides, etcétera. Creemos que este argumento debe ser considerado en la planificación y desarrollo de futuras estrategias o políticas públicas que al respecto se implementen, ya sea a nivel local o nacional, pues podrían fomentar una integración sociocultural efectiva en el sistema educativo. Además, sugerimos que sean desarrolladas a la luz del concepto de ciudadanía intercultural, con el fin de impulsar un proceso creciente de reflexividad sobre la creciente diversidad que caracteriza a nuestras aulas y la generación de prácticas socioeducativas que fomenten su integración educativa.

Finalmente queremos destacar una situación problemática y señalar la diferencia que existe respecto a ella entre los establecimientos educacionales urbanos y rurales. Una parte considerable de los hijos de inmigrantes de la zona han nacido en Chile. Sin embargo, en muchos casos sus padres no poseen sus papeles en regla (visado) o no tienen la nacionalidad chilena, por lo que no reciben los mismos beneficios sociales que los estudiantes hijos de chilenos. Además, han estado sometidos a la imposición cultural que se ejerce desde el aparato escolar y sus prácticas pedagógicas, caracterizadas por un nacionalismo hegemónico. Esto muestra que no existe actualmente una escuela verdaderamente preparada para atender la diversidad sociocultural de la región, al mismo tiempo que hace patente la necesidad de generarla. Además, es necesario subrayar una diferencia significativa: mientras en las escuelas de la zona rural (valles) se tiende a desarrollar un diálogo entre grupos culturales diversos, éste se desarticula o se vuelve menos probable en la ciudad, lo que hace emerger procesos de exclusión que sugieren la presencia de categorías nacionalistas excluyentes que dificultan este diálogo intercultural.

En este contexto, los actores pertenecientes a los colectivos migrantes y a los pueblos originarios han desplegado una serie de estrategias y prácticas para insertarse en el contexto localal generar mecanismos de integración y de asimilación, más que de inclusión intercultural. Consideramos que esta situación no se condice con una escuela que tiene la responsabilidad de valorar la diversidad cultural y permitir que todos los estudiantes sean incluidos y valorados, conservando aquellas tradiciones y costumbres nacionales y culturales más significativas para ellos. 


\section{Referencias citadas}

Aguirre, C. y Mondaca, C. (2011). Estado Nacional y Comunidad Andina. Disciplinamiento y Articulación Social en Arica, 1880-1929. Revista Historia, 44(1), 5-50.

AlSayyad, N. y Castells, M. (2003). Europa musulmana o euro-islam. España: Alianza Editorial.

Alvites, L. y Jiménez, R. (2011). Niños y niñas migrantes, desafío pendiente. Innovación educativa en escuelas de Santiago de Chile. Revista Synergies, 7, 121-136.

Appadurai, A. (2000). Modernity at Large. Cultural Dimensions of Globalization. Minneapolis-London: University of Minnessota Press.

Bassam, T. (2003). Los inmigrantes musulmanes de Europa, entre el euro-islam y el gueto. En Alsayyad, N. y Castells, M. (Eds.). Europa musulmana o euro-islam (pp. 55-79). España: Alianza Editorial.

Castles, S. y Miller, M. J. (2004). La era de la migración. Movimientos internacionales de población en el mundo moderno. México D. F.: UAZ/INM/ Fundación Colosio.

Cepal (2006). Cuatro temas centrales en torno a la migración internacional, derechos humanos y desarrollo. Santiago: Cepal.

Flick, U. (2002). Qualitative Research - State of the Art. Social Science Information, 41(1), 5-24.

Gairín, J. y Castro, D. (2010). Desarrollo educativo al servicio del desarrollo social. Santiago: Fidecap. En http:// ddd.uab.cat/record/123664 (Revisado el 26.12.2015).

Garcés, A. (2015). Migración peruana en Santiago. Prácticas, espacios y economías. Santiago: RIL Editores.

García Canclini, N. (1995) Ms. Consumidores y ciudadanos: conflictos multiculturales de la globalización. Mimeo. México.

Gimeno, S. (2008). Educar por competencias, ¿qué hay de nuevo? Madrid: Morata.

Gobierno de Chile. Ministerio de Desarrollo Social. (2013). CASEN. Santiago.
Guizardi, M. (Ed.). (2015). Las Fronteras del Transnacionalismo. Limites y desbordes de la experiencia migrante en el centro y norte de Chile. Santiago: UCN / Ocho Libros.

Guizardi, M. y Garcés, H. (2013). Circuitos migrantes. Itinerarios y formación de redes migratorias entre Perú, Bolivia, Chile y Argentina en el Norte Grande chileno. Papeles de Población, 19(78), 65-110.

Guizardi, M. y Garcés, H. A. (2012). Mujeres peruanas en las regiones del norte de Chile: Apuntes preliminares para la investigación. Revista Estudios Atacameños. Arqueologia y Antropologia Surandinas, 44, 5-34.

Imilan, W., Márquez, F. y Stefoni, C. (Eds.). (2015). Rutas Migrantes en Chile. Habitar, festejar y trabajar. Santiago: Ediciones Universidad Alberto Hurtado.

Kumar, K. (2002). El Estado Nación, la Unión Europea y las identidades transnacionales. En Alsayyad, N. y Castells, M. Europa musulmana o euro-islam (pp. 81-99). Madrid: Alianza Editorial.

Magendzo, A. (1986). Currículum y Cultura en América Latina. Santiago: PIIE.

Marshall, T. H. y Bottomore, T. (1992 [1950]). Ciudadania y Clase Social. Madrid: Alianza Editorial.

Martínez, J. (2008). La Ciudadanía se convierte en competencias: Avances y retrocesos. En Educar por competencias, ¿qué hay de nuevo? Madrid: Morata.

Mineduc (2011). PEIB-Orígenes. Estudio sobre la implementación de la educación intercultural bilingüe. En Programa Educación Intercultural Bilingüe. Ministerio de Educación, Santiago, Chile. Disponible en: www.mineduc.cl

Mondaca, C. (2003). La Educación Intercultural Bilingüe entre los aymaras de la Región de Tarapacá-Chile: Enfoques y perspectivas en su implementación. Tesis para optar al grado de Magíster en EIB, con mención en Formación de Formadores Aymaras. Universidad de Tarapacá, Arica.

Mondaca, C. (2008). Identidades Sociales y Representaciones Políticas en Conflicto: El Sistema Educativo Chileno en los Andes de Arica, 1884-1929. Revista Anthropologica, 26, 33-62. 
Mondaca, C. y Gajardo, Y. (2013). La Educación Intercultural Bilingüe en la Región de Arica y Parinacota, 19802010. Diálogo Andino, 42, 68-87.

Mondaca, C., Gajardo, Y. y Sánchez, E. (2014). Historia, memoria y ciudadanía intercultural. El reto del siglo XXI para las aulas de la región de Arica y Parinacota, norte de Chile. Interciencia, 39(7), 524-530.

Mondaca, C., Rivera, P. y Aguirre, C. (2013). La escuela y la Guerra del Pacífico. Propuesta didáctica de historia para la inclusión educativa en contextos transfronterizos del norte de Chile. Si Somos Americanos, XIII(1), 123148 .

Mondaca, C., Rivera, P. y Gajardo, Y. (2014). Educación parvularia e inclusión en el norte de Chile. Formando pequeños chilenos en las aulas de Tarapacá. Alpha, 39, 251-266.

Mondaca, C., Gajardo, Y., Muñoz, W., Sánchez, E. y Robledo, P. (2015). Estudiantes migrantes en la región de Arica y Parinacota. Caracterización, distribución y consideraciones generales. En Guizardi, M. (Ed.). Las Fronteras del transnacionalismo. Limites y desbordes de la experiencia migrante en el centro y norte de Chile (pp. 258180). Santiago: UCN / Ocho Libros.

Pavez, I. (2012). Inmigración y racismo: experiencias de la niñez peruana en Santiago de Chile. Si somos Americanos, XII(1), 75-99.

Piñuela, J. (2002). Epistemología, metodología y técnicas del análisis de contenido. Estudios de Sociolinguistica, 3(1), 1-42.

Poblete, R. (2009). Educación intercultural en la escuela de hoy: reformas y desafíos para su implementación. Revista Latinoamericana de Educación Inclusiva, 3(2), 181-200.

Pulido, C. (2007). Migración, Transnacionalidad, Integración y Ciudadania: los peruanos en la zona Norte de Chile. Tesis Master Estudios Latinoamericanos. Leiden, Universidad de Leiden.

Riquelme, J. y Alarcón, G. (2008). El peso de la historia en la inmigración peruana en Chile. Revista Polis, 20(7), 299-310.
Rojas, N. y Vicuña, J. (2014). Migración y trabajo. Estudio y propuestas para la inclusión sociolaboral de migrantes en Arica. Santiago: Ediciones Universidad Alberto Hurtado.

Sorensen, N. N. y Gammeltoft-Hansen, T. (2013). Introduction. En The Migration Industry and the Commercialization of International Migration (Global Institutions) (pp. 1-23). Nueva York: Routledge.

Stefoni, C. (2003). Inmigración peruana en Chile. Una oportunidad a la integración. Santiago: Universitaria.

Stefoni, C. (2004). Inmigración y ciudadanía: la formulación de comunidades peruanas en Santiago y la emergencia de nuevos ciudadanos. Revista Política, 43, 319-336.

Stefoni, C. (2005). Inmigrantes transnacionales: la formación de comunidades y la transformación en ciudadanos. Lima: Instituto de Estudios Peruanos.

Tapia, M. y González, A. (Comps.). (2014). Regiones Fronterizas: Migración y los desafíos para los Estados nacionales latinoamericano. Santiago: RIL Editores.

Unesco (2015). La Educación para Todos, 2000-2015: logros $y$ desafios. París: Unesco.

Vargas, V. (1997). Un debate feminista en curso. En Hola, E. y Portugal, A. (Eds.). La ciudadania a debate (pp. 5585). Santiago: Ediciones de las Mujeres, 25.

Vicuña, J. y Rojas, T. (Eds.). (2015). Migración en Arica y Parinacota. Panorama y tendencias de una región fronteriza. Santiago: Ediciones Universidad Alberto Hurtado.

Willis, P. y Trondman, M. (2002). Manifesto for Ethnography. Cultural Studies - Critical Methodologies, 2(3), 394-402.

Winkler, D. y Cueto, S. (2004). Etnicidad, Raza, Género y Educación en América Latina. Santiago: PREAL.

Yubal-Davis, N. (1997). Mujeres, ciudadanía y diferencia. En Hola, E. y Portugal, A. (Eds.). La ciudadanía a debate (pp. 35-53). Santiago: Ediciones de las Mujeres, 25. 